\title{
Management of foreskin problems
}

\author{
P M Lafferty, F B MacGregor, W G Scobie
}

\begin{abstract}
One hundred consecutive cases of boys with foreskin problems referred to local paediatric surgeons in the Edinburgh area were studied. Fifty five underwent circumcision and the remainder were managed more conservatively with or without the use of local or general anaesthetic. Although sometimes avoiding general anaesthetic, the more conservative methods involved more frequent visits to the clinic, a larger number of complications, and a longer follow up period.

Despite the vogue for conservatism, circumcision still has an important part to play in the management of troublesome foreskins in children.
\end{abstract}

Circumcision is a very old and widely practised surgical procedure. Today, in many countries such as the United States, the decision to circumcise is made by the parents. A recent report revealed that the most important factor associated with the decision to circumcise was whether or not the father was circumcised. ${ }^{1}$ This routine practice continues despite policy statements by the American Academy of Pediatrics and the American College of Obstetrics and Gynecology. ${ }^{2}$

Neonatal circumcision is not a routine procedure in the United Kingdom, but a large number of infants and school age boys are referred to surgical paediatric departments with foreskin problems for possible circumcision.

The presenting complaints vary from individual to individual. Most frequently symptoms appear related to degrees of tightness of the foreskin:from overt phimosis associated with a pin hole meatus to failure to fully retract the foreskin due to congenital adhesions remaining between the glans and foreskin. Extreme phimosis may impede urinary flow, the small voiding orifice causing the foreskin to balloon during micturition.

Localised infection and inflammation together constitute a common cause for referral with foreskin problems, either alone or together with symptoms of phimosis. Balanitis (inflammation of the glans) although often quoted as a major presenting complaint, is in fact much less common than posthitis (inflammation of the foreskin). Retention of smegma, together with the gradual breakdown of congenital adhesions may significantly contribute to localised irritation and inflammation in and around the foreskin as it gradually softens and dilates, allowing full retraction usually by the fifth or sixth year.

Renewed interest in conservation of the fore- skin and the advent of topical anaesthetic creams, such as Emla (eutectic mixture of local anaesthetics (lignocaine and prilocaine), Astra) ${ }^{3}$ has prompted a prospective analysis of methods of management in the Edinburgh area.

\section{Patients and methods}

One hundred consecutive patients with foreskin problems, referred to the two Edinburgh paediatric surgical units (the Royal Hospital for Sick Children and the Western General Hospital) were analysed over a six month period. All children referred were seen by one of four consultant paediatric surgeons or a career senior registrar. A proforma was completed at the initial consultation that recorded the patient's details, reasons for referral, and the treatment implemented. All operative procedures, including Emla lysis, were performed by the full range of medical staff, from consultant to senior house officer.

Follow up was to patient discharge. Statistical analysis of figures was achieved by one way analysis of variance and Mann-Whitney tests.

\section{Results}

Reasons for referral are shown in table 1. The most common reasons for referral as witnessed by the referring letter or the parental history related to tightness of the foreskin and/or recurrent infection. Where phimosis was apparent it was categorised by the attending surgeon as either pin hole $(n=54)$ or meatus visible $(n=$ 46). Only $8 \%$ of referrals requested circumcision on religious grounds. Four patients required no treatment and were discharged.

The basis on which the decision to adopt either surgical or conservative treatment was made ultimately on personal preference of the attendant surgeon. Recurrent infection, pin hole meatus associated with ballooning on micturition, and failed conservative management, however, were regarded as relative indications for circumcision. Forty nine patients had circumcision performed after their initial visit to the clinic.

Table 1 Presenting complaints in 100 consecutive cases

\begin{tabular}{ll}
\hline & No of patients \\
\hline Phimosis & 49 \\
Infection & 39 \\
Ballooning & 17 \\
Failure to retract & 24 \\
Religion & 8 \\
Parental request & 0
\end{tabular}

Some boys had more than one presenting complaint. 
Persistent preputial adhesions or failure to fully retract the foreskin (both with and without significant phimosis) attracted a largely conservative approach with 13 patients undergoing Emla lysis (as outlined by MacKinlay ${ }^{3}$ ) and 26 undergoing preputial stretch/adhesion lysis under general anaesthesia.

In eight patients in whom the symptoms were of minimal persistent adhesions only, an expectant policy was adopted; this involved gentle foreskin retraction being taught to the parents and practised at home. Not surprisingly in this latter group, in whom the symptoms were very mild, there were no complications. The mean number of total hospital visits, including the first, were recorded and are shown in table 2.

Those in the Emla group visited the department 2.9 times on average. Those undergoing preputial stretch and circumcision visited a mean of 3.4 and 2.8 times respectively. Comparing all three groups, there was an overall statistical difference between the mean number of hospital visits (analysis of variance, $\mathrm{p}<0.005$ ). A highly significant difference occurred between the preputial stretch/adhesion lysis group and circumcision groups (Mann-Whitney test, $p=0 \cdot 0006$ ). There was no significant difference between the mean number of hospital visits in the Emla lysis and circumcision groups. It is noted however that the practice at the Royal Hospital for Sick Children was to carry out Emla lysis, if indicated, at the initial visit, thus decreasing the number of attendances. At the same unit, follow up of circumcisions was often carried out by the district nurse, again decreasing the number of hospital attendances.

Two of the 13 boys (15\%) in the Emla group continued to have problems resulting in subsequent circumcision (table 3 ). Of the 26 boys who underwent preputial stretch, seven $(27 \%)$ reported persisting problems of these four pro-

Table 2 Total numbers of hospital visits (including the first)

\begin{tabular}{lll}
\hline & No of patients & $\begin{array}{l}\text { Mean No visits/ } \\
\text { patient (range) }\end{array}$ \\
\hline Emla lysis & 13 & $2 \cdot 9(2-5)$ \\
Preputial stretch & 26 & $3 \cdot 4(2-5)$ \\
Circumcision & 49 & $2 \cdot 8(2-4)$
\end{tabular}

Table 3 Complications

\begin{tabular}{|c|c|c|c|}
\hline & $\begin{array}{l}\text { No of } \\
\text { patients }\end{array}$ & $\begin{array}{l}\text { No }(\%) \text { of } \\
\text { complications }\end{array}$ & Action \\
\hline Emla lysis & 13 & $\begin{array}{l}2(15) \\
\text { Residual adhesions }\end{array}$ & Circumcision \\
\hline $\begin{array}{r}\text { Preputial } \\
\text { stretch }\end{array}$ & 26 & $\begin{array}{l}7(27) \\
\text { Persistent ballooning } \\
\quad(n=1) \\
\text { Residual adhesions } \\
\quad(n=1) \\
\text { Recurrent phimosis } \\
\quad(n=4) \\
\text { Repeated infection } \\
\quad(n=1) \\
4(8) \\
\text { Crusting/bleeding }\end{array}$ & $\begin{array}{l}\text { None } \\
\text { None } \\
\text { Circumcision } \\
\text { Preputial } \\
\text { stretch } \\
\text { None }\end{array}$ \\
\hline
\end{tabular}

ceeded to circumcision and one had a further preputial stretch, all of which required general anaesthesia. Of the 49 boys who underwent circumcision as initial treatment, only four $(8 \%)$ reported problems and none required further operative treatment.

\section{Discussion}

Forty nine of 100 boys referred by their family doctors to two sister paediatric surgical units in Edinburgh had circumcision as the primary management of the presenting foreskin problem. A further six patients underwent circumcision after failure of foreskin preserving measures which included preputial stretch/adhesion lysis under general or local (Emla) anaesthetic. The remainder were managed by more conservative methods, with or without local or general anaesthetic. Only a small number of circumcisions were carried out for religious reasons in the Edinburgh area where the population of ethnic minorities is small.

Emla cream has proved to be useful for local anaesthesia before adhesion lysis in selected, compliant patients. In addition, it is recognised that this method is appropriate for those boys with persistent preputial adhesions but not for those with any significant degree of phimosis. ${ }^{3}$

A complication rate of $27 \%$ after preputial stretch/adhesion lysis is noted; five of the seven boys with continuing symptoms were noted to have 'pin hole meatus' at the first visit. This indicated a need for improved patient selection in this particular treatment group.

Surveys have shown that the uncircumcised child has a higher risk of foreskin/glanular problems compared with the circumcised child $(14.0 \%$ v $6 \cdot 0 \%$ and $18 \cdot 8 \%$ v $11 \cdot 1 \%) .{ }^{4}$ Stenram et al showed that meatal stenosis occurred in up to $11 \%$ of boys after circumcision. ${ }^{6}$ The argument against circumcision because of the risks of general anaesthesia are now less relevant with the advent of safer anaesthetic agents, paediatric trained anaesthetics, and modern monitoring equipment.

Although conservatism is now the mode in foreskin problems, it often increases the number of hospital attendances, and had a higher complication rate in this series.

The authors would like to thank Mr W Bissett, Mr G MacKinlay, and $\mathrm{Mr} J \mathrm{Orr}$ for allowing us to report their patients in this study.

1 Brown MS, Brown CA. Circumcision decision: prominence of social concerns. Pediatrics 1987;80:215-9.

2 Evanston IL. Guidelines for perinatal care. American Academy of Pediatrics and American College of Obstetricians and Gynecologists, 1983:87.

3 MacKinlay GA. Save the prepuce. Painless separation of preputial adhesions in the out-patient department. $B M \mathcal{F}$ 1988;297:590-1.

4 Herzog LW, Alvarez SR. The frequency of foreskin problems in uncircumcised children. Am $\mathcal{F}$ Dis Child 1986; 140:254-6.

5 Fergusson DM, Lawton JM, Shannon FT. Neonatal circumcision and penile problems: an eight year longitudina study. Pediatrics 1988;81:537-41.

6 Stenram A, Malmfors G, Okmian L. Circumcision for phimosis: indications and results. Acta Paediatr Scand 1986;75:321-3. 